\section{Early-warning System Needed}

An important problem to be solved is accomplishment and substantiation of an early-warning system for the entire SPR. From the viewpoint of the sustainable development of the region, the highest priority problems are the following:

1) accomplishment and substantiation of an optimal environmental monitoring system for the SPR, based on the application of both in situ and remote-sensing observation data;

2) numerical simulation modelling of land-use and water-resources exploitation under conditions of increasing anthropogenic loads;

3) studies of anthropogenically-influenced cycles of matter and energy for various natural systems and the whole SPR, as well as changes in the chemical composition of the environment under the impact of such processes as pollution, acidification, salinization, erosion, deforestation, and eutrophication;

4) assessments of stability limits for various ecosystems subject to anthropogenic impact; and

5) influence of environmental degradation on human health.

A special place belongs to problems of atmospheric and sea pollution. In the case of atmospheric pollution, the aim is to simulate changes in the chemical composition of the urban atmosphere with special emphasis on surface and tropospheric ozone dynamics - in view of its impact on human health, as well as on atmospheric aerosol transport and transformation (including transboundary transport) resulting from heterogeneous chemical reactions on particles. Aerosol dry- and wet-deposition processes deserve special attention in the context of toxic pollution of soils and waters. Drinking-water and contaminated agricultural production are practical aspects of the problem.

\section{Means of Solution?}

Towards solving the above-mentioned problems, the following means will be tested:

- techniques of regional-scale optimal planning-observing systems based on combined utilization of in situ and remote-sensing data;
- new approaches of remote sounding, with special emphasis on retrievals of atmospheric aerosol properties and hydrooptical parameters (concentration of phytoplankton, suspended matter, and dissolved organic matter), developed and verified on the basis of combined in situ and satellite (i.e. SeaWiFS*) observations; 3-D dynamic photochemical numerical models to simulate minor gas components' dynamics (a priority is surface ozone), as well as aerosol transformation and transport in the atmospheric boundary layer, verified by comparison with combined in situ and remote-sensing observations.

The eventual aim of the above Project is substantiation and accomplishment of an early-warning system concerning dangerous levels of pollutants in the atmosphere and natural waters (including assessments of transboundary transport). Such a system may be used for environmental management purposes.

\section{REFERENCES}

Gore, A. (1993). Earth in the Balance: Ecology and Human Spirit. PLUME, New York, NY, USA: 408 pp.

KondRatyeV, K.Y., Danilov-Danilyan, V.I., DonchenKo, V.K. \& Losev, K.S. (1993). Ecology and Politics. RAS, St Petersburg, Russia: 286 pp. (in Russian).

WeIsZÄcker, E.U. von (1994). Earth Politics. Zed Books Ltd, London and New Jersey: $243 \mathrm{pp}$.

KIRILL YAKOVLEVICH KONDRATYEV, Counsellor
Research Centre for Ecological Safety
18 Korpusnaya Street
197042 St Petersburg
Russia,
$\quad \&$
OLEG MIKHAILOVICH POKROVSKY, Laboratory Chief
Main Geophysical Observatory
7 Karbysheva Street
194018 St Petersburg
Russia.

* In answer to our query about this, Academician Kondratyev explained (in litt.) that is "is the title of an instrumentation set intended for measuring the sea colour.' - Ed.

\title{
Conservation and Landscape of Historical Sites in India
}

India is a country with a vast historical background. Through the ages, different rulers ruled different parts of the country for different periods, leaving their impact on the territories concerned in the form of:

(i) development of a region, e.g. construction of forts;

(ii) development of areas, e.g. palace complexes, temple complexes, market places; and

(iii) development of recreational areas, e.g. palace gardens, public gardens, play areas, squares, avenues, river banks, lakes, and reservoirs.

These things were built according to the respective culture, climatic conditions of the region, and functional requirement of the structure. As a result, we find a vast variety of historical sites spread all over the country, displaying a wide range of historical backgrounds. As time passes, the functional aspects of these areas/sites undergoes change, leading to neglect of the importance of the building and site, so that it becomes necessary to consider due preservation as well as conservaton of such places.
Conservation will chiefly be activated after realization that the natural and cultural resources of India are being eroded at an alarming rate. Some basic principles guiding the preservation and restoration of ancient buildings were defined for the first time in 1931, in a document known as the Athens Charter. Since 1903, India has been following the essential principles enshrined in earlier Charters, which were further modified and moulded into a Government Resolution in 1915 and published as a 'Conservation Manual'.

Against this background of current concepts, notions, and methods of conservation, we find that, while the methods of conservation followed in India are good and the outcome of following them is often of a commendable standard, the concept of conservation of a monument together with its surroundings, including the vegetation, has not gained any currency here. Thus the concept of conservation of an area and its landscape is quite new in India, where the governments' responsibility in conserving cul- 
tural heritages is limited to the monuments. Many landscapes and the neighbourhood of the monuments thus fall outside the purview of the governments' responsibility and, as such, are increasingly vulnerable to misuse, damage, encroachments of commercial activities, and even extinction in the face of modernization, leading to unrecoverable cultural, social, and environmental, loss.

At a time when awareness of the need for architectural conservation is taking root more firmly than hitherto quite widely in the world, the relevance of landscaping around historical sites seems destined to gain in importance. The undersigned proposes to study the different steps taken by governments and private agencies in India as well as in other countries regarding this subject. Useful critical analysis of those steps, and comments on specific guidelines, should result from this study.

RAHUl D. PATEL

P.G. Programme in Landscape Architecture

School of Architecture

Centre for Environmental Planning \& Technology

Navarangpura

Ahmadabad 380009

India.

\section{The Namibian Free-ranging Cheetah}

$\mathrm{T}$ he Cheetah Conservation Fund (hereafter cited as CCF or the Fund) has been active in Namibia since April 1991. The Fund's mission is to secure habitat for the longterm survival of Cheetahs (Acinonyx jubatus) and their ecosystems through multidisciplined and integrated programmes in research, conservation, and education. The Fund conducts independent and collaborative research, disseminates information, and recommends conservation management techniques. Our research focuses on: identifying important farmland ecocomplexes and component ecosystems that are necessary to sustain healthy Cheetah populations; collecting biological samples to understand the overall health and genetic make-up of the wild populations; and radio-tracking Cheetahs to learn more about their movements through farms and to monitor Cheetahs in areas where new livestock and wildlife management practices are being tested. Programmes developed in Namibia are being adapted for use in other African countries where the Cheetah is in need of protection.

Limited research has been done on Cheetahs outside of protected reserves where the larger populations are found but these are in direct conflict with livestock farmers and by them domestic animals are killed in considerable numbers. The $\mathrm{CCF}$ is addressing this conservation issue by working directly with those people who have problems with this predator, and who, in the end, will determine if the Cheetah is to have a future habitat on their lands.

The largest remaining population of Cheetahs is found in Namibia, where $90 \%$ live in a contiguous area of over $275,000 \mathrm{sq} . \mathrm{km}$ of commercial livestock farmland that produces cattle, sheep, goats, and wildlife. Farmers have successfully removed most of the other large predators, and many would like to do so with the Cheetah, to reduce livestock losses. Cheetahs are known to kill small stock and calves up to six months of age, but are blamed for far more losses than they are actually responsible for. Although classified as a protected animal, a Cheetah may be shot in order to protect one's life or property. The problem is that most farmers practise preventive management - eliminating the Cheetah indiscriminately by either shooting whenever one is seen or after live-catching them in traps.

\section{Assessing the Current Situation}

To assess the Cheetah's situation today, we looked back into recent history to understand the circumstances which have led to its success as indicated by numbers on Namibian farmlands, and its subsequent rapid decline. These circumstances can be attributed largely to the farming environment and to ecological changes that have occurred on the farmlands. The first phase of our long-term programme was an in-depth survey in districts of the country where Cheetahs still exist. Our survey included identifying general statistics, Cheetah distribution patterns, the vegetation and overall conditions of the land, the availability of prey, farmers' interaction with Cheetahs and other animal wildlife, and numbers of livestock and current livestock and game management practices. Some 385 farms, covering over $2,600,000$ hectares ( $15 \%$ of the cattle farms of Namibia) were surveyed in the north-central region of the country.

Over the years, the biodiversity of these extensive farmlands has changed drastically. There has been an overutilization of the land due to a lack of understanding of the limitations of the ecocomplexes and their component ecosystems. With the development of waterholes in the early part of the century, more of the animal wildlife became resident on the farmlands and began competing with the livestock for water and food. Consequently the animal wildlife, competing with the domestic livestock, was killed off in high numbers.

In the 1960s the vegetation of the land began to change, due to a severe drought, overgrazing, and the previous reduction of large herds of migratory game. Along with the farmland development came also the conflict with large and dangerous predators. Protective measures for livestock

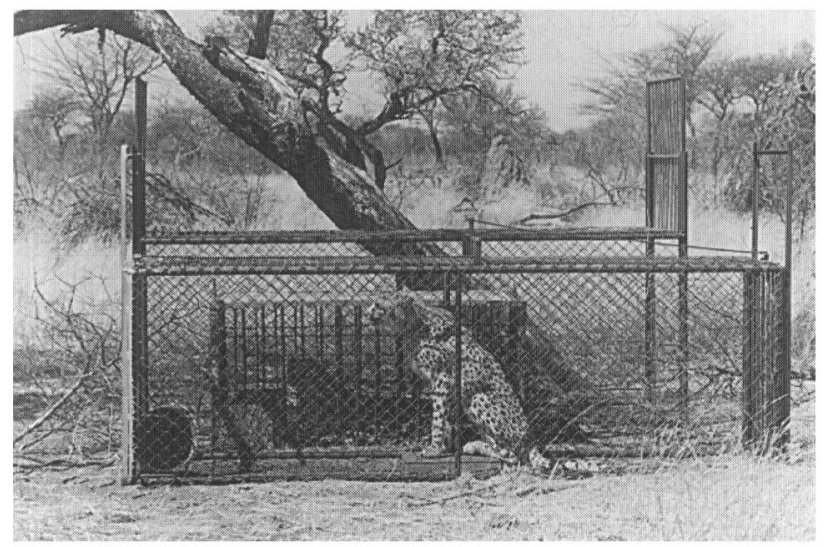

FIG. 1. Two Cheetahs recently caught in a live-trap at a 'playtree', with obviously sloping trunk, where Cheetahs often come to mark their territory. Traps or capture cages are legally set by farmers in Namibia. One Cheetah is in the capture cage in the foreground while a second is in a smaller holding cage behind. The two cats will be radio-collared and released by the Cheetah Conservation Fund after tranquilizing them, taking a complete set of measurements, and collecting blood samples for analysis of the overall health and genetic make-up of the free-ranging Cheetahs. Adult Cheetahs' home ranges can extend up to $1,500 \mathrm{~km}^{2}$ on Namibian livestock farmlands. Cheetahs prefer to prey on wild game rather than on livestock. (Photo: Laurie Marker-Kraus.) 